\title{
A Note on How to Read This Book
}

THIS BOOK has many levels, and it can be read in many different ways. I strongly recommend that you read it from beginning to end, so you can see the whole picture of fossil fuels, politics, and technology from Siberia to the European Union. But if you are short of time and are reading the book with a specific goal in mind, one of the following strategies may be the right one. If you are a student or scholar of political science, international relations, or a related field, read the theoretical chapters, 1 through 3 , and then turn to the empirical case study chapters, 4 through 6 , as examples of the issues discussed in the theoretical chapters. If you are using the book as part of an undergraduate course, I recommend that you assign all its chapters and encourage your students-as they work through the empirical chapters - to actively make use of appendices A (key technical terms), B (key actors), and C (chronology), and also to pay close attention to the explanatory notes. In particular, if you are using the book as part of an undergraduate course on energy politics, I encourage you to use appendix $\mathrm{A}$ as the basis for assignments on the impact of the use of different energy technologies. If you are reading the book for pleasure and out of a general interest in the region, I recommend that you read chapter 1 and then move directly to the empirical case study chapters, letting your imagination roam the road between Siberia and Germany, and returning to chapters 2 and 3 once that road trip has left you craving more theoretical explanations. 
